\title{
Long-term payoffs of near-term low-carbon deployment policies
}

Gokul C. Iyer ${ }^{a, b, c}$, Leon E. Clarke ${ }^{b}$, James A. Edmonds $^{b}$, Nathan E. Hultman $^{a}$,

Haewon C. McJeon ${ }^{b}$

${ }^{a}$ School of Public Policy, University of Maryland

${ }^{\mathrm{b}}$ Joint Global Change Research Institute, Pacific Northwest National Laboratory and University of Maryland

${ }^{c}$ Corresponding author

Email-addresses:

gokul.iyer@pnnl.gov, leon.clarke@pnnl.gov, jae@pnnl.gov, hultman@umd.edu, haewon.mcjeon@pnnl.gov

\begin{abstract}
Recent climate change negotiations indicate that near-term policies to address climate change are likely to vary across countries with countries employing a range of different policy options. One option frequently mooted at the national level is to promote, via policy, the deployment of lowcarbon technologies. Promoting the deployment of low-carbon technologies can involve a nearterm cost, if such technologies are more expensive overall, or require more upfront capital, than emitting alternatives. However, it lowers future costs of emissions abatement by reducing emissions in the near-term and potentially accelerating rates of improvement in targeted lowcarbon technologies. We derive a globally cost-effective, near-term international technology
\end{abstract}


investment strategy to achieve a long-term climate goal and show that it employs a diversified international technology investment portfolio across countries. We also explore the degree to which independent national technology deployment policies align with collaboratively determined regimes. We show that conditions exist under which there are substantial gains to international cooperation in the deployment of diverse low-carbon technologies and also circumstances in which domestic outcomes align with the global outcome.

Keywords: Technological change, integrated assessment model, climate change mitigation, green, policy, spillover

\section{Introduction}

Recent climate change negotiations indicate that near-term actions to address climate change are likely to occur on the basis of national priorities and preferences. Leading up to the $21 \mathrm{st}$ Conference of Parties under the United Nations Framework Convention on Climate Change (UNFCCC) in December 2015 at Paris, countries are submitting their Intended Nationally Determined Contributions (INDCs), which detail their plans for climate change mitigation in the period to 2025 or 2030 . As key emitters have looked at their own options for reducing emissions domestically, increased deployment of low-carbon technologies is an important component of the mitigation opportunities for many of them. Countries are therefore at an important stage of setting near to medium-term goals for mitigation that they will then need to implement domestically via policy. For example, in the recent US-China joint announcement on climate change, China's commitments focused on increasing the share of non-fossil energy sources in the near-term (The White House, 2014). Likewise, in the recent US-Brazil joint statement on climate 
change, the countries expressed an intention to increase the share of renewables in electricity generation to $20 \%$ by 2030 (The White House, 2015).

A fundamentally important question for these countries is the appropriate balance between proven and new technological approaches, and to what extent they can or should pursue policies that help drive cost reductions either via global markets or via domestic policies. A complication is that promoting the deployment of low-carbon technologies through policies can involve a cost in the near-term, even as such policies can pay off in the long-term, through reduced costs of long-term emissions abatement, improved competitiveness of domestic industries leading to expanded exports and improved energy security.

This paper focuses on reduced costs of long-term emissions abatement due to near-term lowcarbon deployment policies. There are two avenues for reducing long-term abatement costs (Figure 1). First, there is a near-term abatement effect. Promoting the deployment of low-carbon technologies may avoid lock-in into carbon-intensive technologies - by replacing carbonintensive fossil fuel with low-carbon sources, leading to emissions abatement in the near-term. Climate change is a long-term cumulative emissions problem. Thus, for any long-term limit on climate forcing, emissions abatement in the near-term reduces the need for abatement in the long term, resulting in reduced long-term abatement costs. Second, there is a technological change effect - promoting the deployment of low-carbon technologies could lead to improvements in technology costs, reducing long-term abatement costs (Goulder and Mathai, 2000; Schneider and Goulder, 1997). An important question in this context is, how do these effects interact and what does this mean for the most effective mix of near country-level deployment policies? Should all countries pursue the same technologies? Is a diversified approach more effective? 
The potential answer to these questions is complicated by the fact that the above effects have public goods characteristics. Emissions abatement is a public good because most greenhouse gases are well-mixed (that is, they have lifetimes long enough to be relatively homogeneously mixed in the troposphere). Likewise, technological change that occurs domestically due to a domestic deployment policy may spill over to firms globally, also representing a public good. Hence, what is cost-effective globally may not be so from the domestic perspective.

In this study, we examine the divergence between long-term domestic and global outcomes in the context of an international approach to emissions abatement, in which countries promote low-carbon technologies in the near-term by means of deployment policies. To illustrate this divergence, we investigate an example in which China and USA have the option to promote wind or solar technologies in the near-term. Assuming that the countries make near-term technology investment choices in a non-cooperative game, we show that the nature of the divergence between the domestic outcome (derived as the Nash equilibrium) and the global outcome (derived as the globally cost-effective strategy) depends on a range of factors, including the nature of technological change, technology spillovers, and domestic mitigation potentials. It is important to note that the aim of this analysis is not to represent any particular real-world policy, but rather to illustrate, by means of an example, the various forces at work, how they interact, and the implications for international collaborations on climate change mitigation and technology.

The paradox that individually rational strategies lead to collectively irrational outcomes has been discussed at length (Olson, 1965) and illustrated for a broad range of issues such as supply chain management (Cachon, 2001; Cachon and Netessine, 2004) and even international climate change negotiations (Barrett, 2003). The principal contribution of this paper is to illustrate these effects 
in the context of low-carbon technology deployment policies and international climate change mitigation, and in doing so, to highlight opportunities for international and domestic policies.

In addition, our study extends existing analyses based on energy-economic models that have explored the economics of "sub-optimal" near-term policies in the context of long-term climate change mitigation. Such studies have represented near-term action as a price on carbon (Bosetti et al., 2009a; Bosetti et al., 2009b; Jakob et al., 2012), assessed the effectiveness of different policy options (Fischer and Newell, 2008) or focused on the interaction effects of carbon-price based and technology policies (Böhringer and Rosendahl, 2010; Fankhauser et al., 2010; Pethig and Wittlich, 2009). In contrast to the above studies, Clarke et al. (2010) explored the role of advanced technologies being available only in the United States versus globally and found that domestic and global benefits of achieving a stringent climate goal in these cases are vastly different. For example, if advanced technologies are made available everywhere but the United States, global abatement costs are lower than if advanced technologies are available only in the United States. On the other hand, if advanced technologies are made available in the United States alone, abatement costs to the United States are higher. This paper builds off the Clarke et al. (2010) study by introducing elements of heterogeneity in near-term technology choice and analyzing long-term implications from the perspectives of both, the globe as well as the individual countries undertaking deployment policies in the near-term.

The rest of the paper is organized as follows. First, we review some of the long-term payoffs of near-term deployment policies to promote the deployment of specific low-carbon technologies. Next, we describe the construction of the analysis in which we consider the example of China and USA promoting wind and solar in the near-term. Following this, we use the Global Change Assessment Model (GCAM) to understand how different configurations of near-term 
deployment policies impact domestic and global outcomes for the long-term. The final section of the paper concludes with a discussion of the broader implications of the results.

\section{Review of long-term payoffs of near-term deployment policies}

Examples of policy instruments to promote the deployment low-carbon technologies include renewable portfolio standards (which is prevalent in many states of the USA and some European countries), feed-in-tariffs (common in majority of European countries, Australia, Canada and some developing countries), exempting energy taxes on low-carbon technologies, production tax credits and subsidies (for example for nuclear power in the USA). Although such policies involve a cost in the near-term, they could pay off in the long-term. In this section, we three long-term payoffs of promoting the deployment of low-carbon technologies through nearcountry level deployment policies in the near-term, namely, reduced long-term abatement costs, early-mover advantages and improved energy security.

\subsection{Reduced long-term abatement costs}

An important long-term payoff of promoting the deployment of low-carbon technologies is that it could lead to reduced costs of emissions abatement in the long-term. Two main effects lead to this. The first is the near-term abatement effect. Technological and institutional interdependencies lead to considerable inertia in technological systems. Decisions made in the past may lead to technologies getting locked into particular configurations. Such co-evolution of technology clusters over time, also referred to as path dependency, creates constraints for the diffusion of low-carbon technologies, leading to a "carbon lock-in" (Arthur, 1989; Grübler et al., 1999; Unruh, 2000). Deployment policies to promote the deployment of low-carbon technologies 
help in avoiding carbon lock-in - they displace carbon-intensive fossil fuel technologies and add low-carbon energy to the energy system, leading to emissions abatement.

Near-term abatement is a public good because greenhouse gases are well mixed. Consequently, any abatement achieved by the investor country also applies to the globe. Hence, if, in the longterm, there is a global climate mitigation regime, abatement in the near-term would result in lower global abatement in the long-term, because, the more abatement that occurs in the nearterm, the less that needs to occur globally in the long-term. This would lead to reduced global abatement costs in the long-term. In addition, reduced global abatement in the long-term also implies reduced abatement by the investor country, resulting in reduced long-term abatement costs for the investor country as well.

The second effect is the technological change effect. The literature on induced technological change suggests that promoting the development and deployment of technologies could lead to improvements in technology costs (Clarke et al., 2006; Clarke and Weyant, 2002; Jaffe et al., 2003; Popp et al., 2010). For example, the performance of a technology could improve as experience with the technology accumulates. This concept, widely known as learning-by-doing occurs as repetitive manufacturing tasks result in an improvement in the production process, which can also be supported by a number of forces such as increases in labor efficiency, new processes and changes in production methods, changes in the administrative structure, etc. Other avenues through which such improvements occur include users' experience and feedback effects as sources of learning and further R\&D and tacit learning through increase in the stock of knowledge arising out of exchange of information about product characteristics and user requirements between various actors such as research laboratories, industry, end-users and policy makers (see Kahouli-Brahmi (2008) for a detailed taxonomy and description of such 
mechanisms). Promoting the deployment of low-carbon technologies could thus generate cheaper technological options and emissions can be reduced at lower costs in the future, potentially leading to substantial economic benefits for the investor countries.

The technological change effect also has public goods characteristics. Technological change that occurs domestically due to a domestic deployment policy may spill over to firms globally. A number of studies have confirmed the presence of such spillovers in the manufacturing sector (Argote et al., 1990; Barrios and Strobl, 2004), semiconductor industry (Irwin and Klenow, 1994), chemical processing industry (Lieberman, 1984) and the nuclear power industry (Lester and McCabe, 1993; Zimmerman, 1982). In a more recent study, Nemet (2012) analyzed a panel of electricity output from wind turbines in California, and found that firms not only learned from their own experience but from the experience of others as well. In the case of low-carbon technologies such as wind, it might also be reasonable to assume that spillovers exist on a global scale - because the global wind market is dominated by few big turbine manufacturers that deliver turbines all over the world and basically use the same technology concepts (Junginger et al., 2005).

The public goods characteristics of the technological change effect described above could influence long-term abatement costs for the globe as well as the investor country. First, as explained earlier, since an emissions abatement technology is cheaper, the investor country would benefit from it for its own emissions abatement. In addition, if the cheaper technology becomes widely available through spillovers, it lowers the cost of emissions abatement in general. This effect would help the investor country even were it never able to utilize the technology itself, since the technology lowers the cost to all parties leading to greater emissions 
reductions by other parties, and thereby reducing the level of effort needed in the investor country itself, further reducing abatement costs for the investor country.

\subsection{Early-mover advantages}

Deployment policies targeted at specific technologies could create early-mover advantages for domestic firms. From the perspective of a firm, an important source of early-mover advantages is technological leadership. Cheaper technological options may arise due to the technological change effect explained earlier; and if those options can be kept proprietary through mechanisms such as patents, it could create barriers to entry for late entrants, creating opportunities for technological leadership. In this case, the returns garnered by the early moving firm are pure economic rents (Lieberman and Montgomery, 1988).

In addition to advantages at the firm level, expansion of a low-carbon industry could lead to increases in overall macro-economic growth through the expansion of export industries. A classic example in the energy industry is that of Denmark. Hansen et al. (2003) found that the Danish wind energy strategy not only improved the international competitiveness of the industry but also compensated for the initial welfare loss.

In addition to the above advantages, expansion of low-carbon industries could create domestic employment opportunities. In the case of renewable energy policies, proponents have argued that compared to fossil-fuel power plants, renewable energy generates more jobs per unit of installed capacity, per unit of power generated and per dollar invested (Kammen et al., 2004; UNEP, 2008; Wei et al., 2010). 


\subsection{Improved energy security}

Many countries promote alternative technologies with the objective of energy security. Industrialized as well as developing nations have shown renewed focus on energy security because of the exceedingly tight oil market and high oil prices and also due to other drivers such as the threat of terrorism, instability in some exporting nations and geopolitical rivalries (Chester, 2010; Yergin, 2006).

To summarize, promoting the deployment of low-carbon technologies in the near-term could pay off for the investor country in several ways, making a rather strong case for specializing in particular low-carbon technologies. However, because technologies have public goods characteristics, if countries were to interact and negotiate with each other on technology deployment, motivated by self-interests (in other words, to specialize in particular low-carbon technologies), we would expect to see a divergence between domestic and global outcomes. For example, if all countries were to specialize in the same low-carbon technology, from the global perspective, long-term abatement costs (assuming long-term global action against climate change) would be greater than the case in which different countries specialize in different lowcarbon technologies. This is because, in the latter scenario, technological improvements in more emissions abatement technologies could become widely available through spillovers, leading to lower global long-term abatement costs compared to the scenario in which all or most countries specialize in the same technology, in which case, spillovers could be redundant. Thus, we expect the globally cost-effective strategy to be a diversified portfolio of investments.

Although we do not examine them in this study, other arguments for a diversified portfolio of investments in technology include diminishing returns to scale of experience and technological knowledge and risk management (Blanford and Clarke, 2003). Knowledge gained out of 
experience or R\&D has been shown to exhibit diminishing returns to scale (Arrow, 1962).

Hence, as marginal returns fall with increased investment, it will be optimal to invest in options that generate higher marginal returns to exploit the most productive range in each option. Likewise, diversification might also provide insurance against any single technology not advancing as fast as expected. Finally, under uncertainty about when and where unexpected technological breakthroughs might arise, diversification could provide the ability to take advantage of such opportunities. ${ }^{1}$

\section{Methods}

\subsection{Example of China and USA promoting wind or solar technologies in the near- term}

In this paper, we consider an example of China and USA having the option to promote wind or solar technologies in the near-term and use the GCAM integrated assessment model (described in the following section) to analyze global and domestic long-term payoffs from reduced longterm abatement costs. The construction of the analysis is given in detail in Table 1.

In our example, both China and USA have the option to apply deployment policies for wind and solar technologies to achieve a fixed installed capacity by 2030. Near-term low-carbon deployment policies are modeled as renewable portfolio standards to achieve an installed capacity of 500 GW by 2030 (roughly consistent with an extrapolation of China's 2017 targets

\footnotetext{
${ }^{1}$ Note that these arguments for diversification hold for individual countries as well. However, in this study, we do not investigate the case in which countries can promote the deployment of different low-carbon technologies through deployment policies, reserving it for future research. The focus of this study is to understand the long-term implications for individual countries investing in deployment policies as well as the globe when countries are motivated by interests to specialize in particular low-carbon technologies.
} 
for wind deployment) (Bloomberg, 2014). ${ }^{2}$ For simplicity in illustrating the key dynamics in play, no other countries undertake mitigation during this period. The selection of countries for the example is based not only on relevance to recent policy discussions, but also differences in expected near-term energy system characteristics in the absence of any targeted deployment policy. For example, China's energy system is dominated by coal and is expected to grow in the near-term (Figure 3A). In contrast, gas and oil account for a significant share in the energy mix of USA, in addition to coal and the size of the energy system is expected to remain stable. The selection of technologies is based on differences in expected near-term market maturities of the technologies in domestic as well as global markets. In our example, the relatively cheaper and mature technology is wind while solar is the relatively immature and expensive technology. In the long-term, we assume that there is globally coordinated action (modeled as a global price on carbon) to achieve $550 \mathrm{ppm} \mathrm{CO}_{2} \mathrm{e}$ by 2100 , a long-term target consistent with keeping global mean temperature rise below $2{ }^{\circ} \mathrm{C}$ (UNFCCC, 2010; Vuuren et al., 2011).

Near-term costs are calculated as the change in both consumer and producer surplus due to the policy. We focus our analysis on long-term payoffs from reduced long-term abatement costs of achieving the $550 \mathrm{ppm} \mathrm{CO}_{2} \mathrm{e}$ target (abatement costs are calculated as the area under the marginal abatement cost curve). In addition, to investigate the impact of including other payoffs on domestic outcomes, we also consider long-term payoffs from improved competitiveness for investor countries, leading to early-mover advantages.

The near-term low-carbon deployment policies will lead to near-term emissions abatement, but they could also lead to technological change in the targeted technologies in the long-term. We

\footnotetext{
${ }^{2}$ We fix the near-term installed capacities across possible deployment policy configurations to focus on the nearterm abatement and technological change effects, keeping other variables fixed. Alternative assumptions about nearterm installed capacities would not materially alter the insights obtained from this analysis.
} 
consider four scenarios to investigate the technological change effect (Table 2). First is the counterfactual scenario in which deployment policies do not lead to any additional improvements in technology costs (the "No additional technological change" scenario). If deployment policies lead to faster improvements in technology costs, the faster improvements may apply only to the country that invests in the deployment policy (the "Faster domestic improvements" scenario) or spill over to other countries. If they do spill over, they may do so after some period of delay beyond 2030 (the "Faster domestic improvements and delayed spillovers" scenario) or immediately in 2030 (the "Faster domestic improvements and immediate spillovers" scenario) (see Figure 2 and Supplementary Information for detailed description of the representation of technology costs). ${ }^{3}$

Finally, in order to test the sensitivity of the results to assumptions about rates of technological improvements, we consider five sensitivity cases in which we vary the rates of technological improvements (Supplementary Table 1). Our central assumptions about the rates of improvements of reference and advanced wind and solar technologies presented in Table 2 are consistent with Clarke et al. (2007) and McJeon et al. (2011). Our sensitivity cases also includes a breakthrough scenario in which promoting solar in the near-term leads to a technological breakthrough in solar technologies such that costs of solar technologies drop to one-fourth that of wind by 2050 and rapidly decrease thereafter.

\footnotetext{
${ }^{3}$ In this stylized representation of technological change, we do not track the sources of technological change, namely, spillovers, experience and $R \& D$, explicitly to avoid the various uncertainties surrounding these elements to influence the insights of the analysis (Clarke et al., 2006; Clarke et al., 2008a; Yeh and Rubin, 2012). As we explain in the subsequent sections, the results of our analyses depend on the presence and level of spillovers and the rate of technological change. In order to understand these effects, we consider a number of sensitivity cases on these variables (see Table 2 for scenarios on the presence and level of spillovers and Supplementary Table 1 and section 5.2 for sensitivities on the rate of technological change).
} 


\subsection{The GCAM integrated assessment model}

This analysis uses the Global Change Assessment Model (GCAM) ${ }^{4}$. GCAM is an integrated assessment model of the global energy, economy, land use, and climate systems (Edmonds et al., 2004; Edmonds and Reilly, 1985; Kim et al., 2006; Sands and Leimbach, 2003). The climate system is represented by the Model for the Assessment of Greenhouse-Gas Induced Climate Change (MAGICC). Outcomes of GCAM are driven by assumptions about population growth, labor participation rates, labor productivity, technology, and policy in fourteen geo-political regions. GCAM uses a 5-year time step, initialized to 2005 with a time horizon of 2095 . It solves for the equilibrium prices and quantities in all energy, agricultural and GHG markets in each time period and in each region. GCAM is a dynamic-recursive model. GHG emissions are determined endogenously based on the resulting energy, agriculture, and land use systems. GHG concentrations, radiative forcing, and global temperature change are determined using MAGICC.

The energy system in GCAM begins with depletable primary resources such as coal, natural gas, oil and uranium along with renewable sources such as solar and wind (at regional levels). These resources can be transformed into to final energy carriers (such as electricity and hydrogen), ultimately used to provide energy services to end users. Each technology in the model has a lifetime, and once invested, technologies operate till the end of their lifetime or are shut down if the variable cost exceeds the market price.

The deployment of technologies in GCAM depends on relative costs and is achieved using a logit-choice formulation which represents decision making among competing options when only some characteristics of the options can be observed (Clarke and Edmonds, 1993; McFadden,

\footnotetext{
${ }^{4}$ The version of the model used in this paper is GCAM 3.2. The most recent version of the model can be downloaded online at: http://www.globalchange.umd.edu/models/gcam/. A detailed description of the model and how the energy system is represented in GCAM is available in Clarke et al. (2008b) and at http://wiki.umd.edu/gcam/index.php?title=Main_Page.
} 
1980; Train, 1993). An important feature of this approach is that not all decision makers choose the same technology option just because its median price is lower than the median price of competing technologies; higher-median-priced options take some market share, though lower median prices command larger market shares.

GCAM allows increased investment in currently preferred fossil fuel technologies leading to a lock-in in such technologies. In scenarios with deployment policy, the preference for fossil-fuel technologies continues to exist - however, their deployments decrease as the deployment of the technology targeted by the policy increases to satisfy the demand for energy.

\section{Results}

\subsection{Effects of deployment policies in the near-term}

To understand the long-term implications of deployment policies, it is useful to first explore the nature of technology deployment absent any near-term policies. In this case, increased investment in currently preferred fossil fuel technologies leads to a lock-in in such technologies resulting in an energy system that is dominated by such technologies in both countries (Figure $3 \mathrm{~A})$. Further, the deployment of wind is larger than solar in both countries because wind is relatively more mature and cheaper - hence more competitive - compared to solar (Table 3 , Supplementary Figure 1). In addition, the deployments of both technologies are greater in China compared to USA because China's energy demand grows far more rapidly. Differences in nearterm deployments can also be explained by differences in resource endowments and domestic preferences. 
Under deployment policies, fossil-fuel energy sources are replaced with low-carbon sources, leading to near-term emissions abatement (Figure 3B). A solar policy leads to greater near-term abatement compared to a wind policy because a solar policy adds more low-carbon energy to the system (note that both, wind and solar policies are modeled to achieve the same cumulative capacity in the near-term and there is less solar initially - see Table 3) (Figure 3B). In addition, since solar technologies are more expensive than wind in the near-term, the overall near-term costs of a solar policy are higher (Figure 3C). Near-term costs for USA and China are different because of differences in mitigation potentials and resource endowments (for example, China's energy system is dominated by coal which is cheaper to displace compared to gas and oil which account for a significant share in the energy mix of USA, in addition to coal).

\subsection{Long-term payoffs from reduced abatement costs}

\subsubsection{Near-term abatement effect}

To study the near-term abatement effect, we look at the scenario in which deployment policies do not lead to any additional technological improvements. In this scenario, any reductions in long-term abatement costs would be due only to the near-term abatement effect. To compare different deployment policy configurations, we define payoff as the reduction in long-term abatement cost with near-term deployment policy relative to the case without deployment policy divided by the near-term cost of the policy: Payoff $=($ Long-term abatement cost without nearterm deployment policy - Long-term abatement cost with near-term deployment policy) / (Nearterm cost of deployment policy). Thus, payoffs in this scenario would be proportional to the ratio of near-term abatement to near-term cost.

China's payoffs are highest when China promotes wind and USA promotes solar because this configuration leads to the highest near-term abatement to cost ratio (Figure 4A). For the same 
reason, payoffs for USA are highest when USA promotes wind and China promotes solar (Figure 4B). Since near-term abatement is a public good, both countries benefit from a solar policy because that leads to more abatement; however, promoting solar is more expensive, creating incentives to free-ride. Each country would prefer to promote the relatively mature and cheaper technology (wind) domestically and free-ride on the benefits of the other country undertaking larger and more expensive abatement.

Assuming that the countries are monolithic, unitary and rational actors with self-interest (selfinterest means that that each country prefers a larger payoff to a smaller one; it also requires that each country does not directly care about the payoff received by the other country), and that the countries make choices in a non-cooperative game with imperfect but complete information, the equilibrium strategy (derived as the Nash equilibrium) is for both countries to promote wind (Supplementary Figure 2). ${ }^{5}$ The China-wind-USA-wind configuration is also the globally costeffective configuration because it leads to the highest near-term abatement to cost ratio (Figure 4C). In other words, from a global perspective, without improvements in technology, there is little reason to invest in the more expensive technology.

\subsubsection{Technological change effect}

When the technological change effect is included - that is, when deployment policies lead to faster improvements in domestic technology costs (that do not spill over to other regions)domestic and global payoffs are higher because access to advanced wind or solar technologies

\footnotetext{
${ }^{5}$ Note that in game theory, the difference between perfect and complete information is important. Perfect information refers to the case where each player knows how the other will act. Here, we assume that the game is played only once and that players make their choices simultaneously, without knowing the other country's choice. Thus, this is a game of imperfect information. Complete information, on the other hand, refers to the case where each player knows the choices that both parties may make, the payoffs associated with every outcome and the preferences of the other player. In addition, we assume that all of this is common knowledge: each player knows that the other player knows these things, each knows that the other knows that it knows these things, and so on (Barrett, 2003).
} 
results in lower long-term abatement costs. However, the equilibrium strategy is for both countries to promote wind. As before, this strategy is also the globally cost-effective one (Figure 4D-F).

In the scenarios in which technological improvements spill over to other regions after a delay or immediately, global access to cheaper wind and solar technologies lowers marginal abatement costs throughout the globe. This effect leads to greater reductions in long-term abatement costs and so, higher payoffs for the investor country even were it never able to utilize the technology itself (Figure 4G-L). This is because, lower marginal abatement costs in the rest of the world drive greater emissions reductions by other regions, thereby reducing the level of effort needed in the investor country itself. However, even with higher payoffs, the equilibrium strategy remains unchanged (both countries promoting wind). This is because, promoting solar in the near-term is expensive and advanced solar technologies would be available irrespective of who undertakes the effort in the near-term, adding to the free-riding incentives discussed earlier.

In contrast, global payoffs are highest when China promotes solar and USA promotes wind. Not only does this configuration lead to the highest near-term abatement to cost ratio, but improvements in both technologies spill over to other regions. In other words, the globally costeffective configuration corresponds to the one in which public goods characteristics of both, near-term abatement and technological change are maximized. This suggests that, from a global perspective, if deployment policies lead to improvements in technology, there may be substantial benefits to a diversified portfolio of investments in both, currently mature as well as immature low-carbon technologies. 


\section{Discussion}

Domestic payoffs presented in the analysis so far could potentially be influenced by two assumptions. First, we have considered one long-term payoff of near-term deployment policies (namely, reduction in long-term abatement costs) and there are several others, such as earlymover advantages and energy security. While a detailed examination of all payoffs is beyond the scope of the present analysis, we include a discussion on how considering one other payoff, namely, early-mover advantages influences domestic long-term outcomes in Section 5.1. We find that a simple analysis of including such advantages does not affect domestic outcomes obtained above.

Second, assumptions regarding future rates of technological improvements induced by near-term deployment policies depend on a number of factors. In the analysis so far, we have assumed that solar technologies remain expensive compared to wind in the long-term, even in the presence of technological improvements. However, these technologies have shown tremendous potential for rapid improvements in the recent past. In addition, technological change in the rest of the world might spill over to the investor countries, inducing faster rates of technological improvements.

Should the relative costs of solar and wind technologies invert, we would expect different results. In Section 5.2, we discuss the sensitivity of our results to assumptions about the rates of technological improvements. We find that under assumptions of rapid technological change for solar technologies, domestic outcomes align with the global outcome.

\subsection{Other long-term payoffs of low-carbon deployment policies}

As discussed in Section 2, promoting low-carbon technologies in the near-term could lead to early-mover advantages for the investor countries. In this section we explore how the inclusion of such advantages influences domestic outcomes in the long-term. 
In this analysis, early-mover advantages are assumed to represent not only economic rents earned by firms in investor countries but also broader impacts on the macro-economy of those countries, such as job creation and expanded exports. One approximation of such advantages would be to consider a fraction of future global market revenue from global sales of the targeted technology. It is important to note that the existence and magnitude of such advantages have been debated. For example, Michaels and Murphy (2009) argued against the employment effect, that is, because low-carbon technologies such as renewables require higher labor input per unit of output compared to fossil fuels, they bring down the overall productivity of the economy, leading to a net welfare loss rather than gain. We therefore consider a range of fractions. In addition, we consider market revenues only until 2050, keeping in mind that early-mover advantages get dissipated under competition and preemptive adoption (Fudenberg and Tirole, 1985; Hoppe, 2000).

As explained previously, under central technology cost assumptions (corresponding to the analyses presented in Figure 4), if countries were to promote low-carbon technologies in the near-term, the globally cost-effective strategy in terms of abatement costs of achieving a stringent long-term climate goal is a diversified approach in which different countries invest in different technologies. In contrast, the cost-effective strategy from the perspective of individual countries is to invest in currently mature and cheaper technologies. The question relevant to our analysis is whether including early-mover advantages affects this outcome and align it with the globally cost-effective strategy.

In this case, solar technologies are more expensive than wind even if deployment policies are assumed to lead to faster technological improvements in the long-term (Figure 2). Hence, in all technological change scenarios, the global demand for solar technologies is lower than wind and 
the future global revenue from the solar market is smaller (Figure 5). As a result, even under optimistic assumptions about the presence and magnitude of early-mover advantages (which are assumed to be proportional to the future global revenue), both countries continue to remain better off promoting wind irrespective of the other country's choice and the equilibrium strategy remains unchanged (Figure 6).

The results suggest that if countries interact with each other and make decisions on low-carbon technology deployment driven by domestic advantage alone—and, importantly, if their investments do not lead to a radical improvement in the relative costs of such technologiessuch decisions will favor currently cheaper alternatives - even if domestic incentives other than reduced long-term abatement costs are taken into account - primarily because such incentives might be closely tied with each other and technological change might influence different payoffs in similar ways. In the above case, solar technologies are more expensive than wind in the longterm in all technological change scenarios. Consequently, long-term payoffs from reduced abatement costs with a near-term solar policy are lower than wind. For the same reason, future demand for solar technologies is lower than wind and hence, the revenue from the global solar market is lower than wind in all technological change scenarios. As a result, long-term payoffs from early-mover advantages with a near-term solar policy are lower than wind, even under optimistic assumptions about the magnitude of early-mover advantages in all technological change scenarios. Therefore, wind remains the dominant strategy in terms of total payoffs from reduced abatement costs and early-mover advantages. However, as we show in the following section (Section 4.2), if deployment policies lead to sufficiently rapid technological improvements, domestic outcomes align with the global outcome even without considering 
early-mover advantages; underscoring the importance of rates of technological change and spillovers in influencing domestic outcomes. ${ }^{6}$

Of course, the above treatment of early-mover advantages is rather simplistic. Neither does it represent feedbacks to the economy, nor does it differentiate across technologies. To demonstrate the latter point, early-mover advantages could vary with the maturity of the technology: in mature technologies such advantages are largely exploited. In contrast, in currently immature technologies, opportunities for such advantages still exist. In spite of these drawbacks, the analysis presented in this section is useful, as a first approximation and a detailed treatment of early-mover advantages is reserved for future analysis.

\subsection{Sensitivity of results to assumptions about rates of technological improvements}

As explained earlier, domestic payoffs could potentially be influenced by our assumptions about rates of technological improvements. We consider a number of sensitivity cases on the assumptions about rates of technological improvements (Supplementary Table 1, Supplementary Figures 3-5). Since solar technologies have shown the potential for rapid technological change (REN21, 2013), a particularly interesting scenario is one in which promoting the deployment of solar technologies in the near-term leads to a technological breakthrough in solar technologies in the future (Figure 7). ${ }^{7}$

In the absence of the technological change effect, domestic and global outcomes in the solar breakthrough scenario are the same as before (Figure 7A-C). However, when the technological change effect is included (assuming no spillovers), the equilibrium strategy shifts to both

\footnotetext{
${ }^{6}$ Note that from a global perspective, early-mover advantages represent a zero-sum transfer. Hence, global payoffs would be the same as in Figure 4.

${ }^{7}$ We do not consider the possibility of a breakthrough in wind technologies because such technologies are relatively mature compared to solar. Also, such a scenario would not give insights different from those derived from Figure 4.
} 
countries promoting solar (Figure 7D-F). This is because, in this scenario, access to the "breakthrough" solar technologies leads to greater reductions in abatement costs and therefore, higher payoffs compared to wind.

In the presence of spillovers, if USA were to promote solar, China would promote wind as promoting wind is cheaper and that would also make improvements in both technologies available to the rest of world, leading to higher payoffs (Figure 7G-L). However, if USA were to promote wind, China would promote solar (although promoting solar is expensive in the nearterm) because that would make the "breakthrough" solar technologies available to the rest of the world. Since "breakthrough" solar technologies are cheaper than wind technologies in the longterm, global access to the former would have a greater influence on global marginal abatement costs compared to wind technologies, ultimately leading to higher payoffs for China. Likewise, if China were to promote solar, USA would promote wind and if China were to promote wind, USA would promote solar. Therefore, the equilibrium strategies shift to China-solar-USA-wind and China-wind-USA-solar configurations (the multiple equilibria obtained in Figure 7 are discussed further in the Supplementary Information). These configurations are respectively, the highest and second highest in terms global payoffs. Thus, if promoting the deployment of currently expensive technologies leads to sufficiently rapid technological improvements in such technologies in the long-term and if such improvements spill over globally, domestic outcomes align with the globally cost-effective outcome. These results underline the importance of the rate of technological change and spillovers in influencing domestic outcomes and potentially aligning them with the global outcome. 


\section{Conclusions and policy implications}

International efforts to mitigate emissions are moving toward a coordinated but bottom-up approach where countries take actions based on national priorities and preferences. One popular near-term action under consideration in many countries is to promote the deployment of lowcarbon technologies in the near-term because that can pay off in the long-term through several avenues such as reduced costs of future emissions abatement, early-mover advantages and energy security. In that context, a key question facing domestic policy makers is the appropriate mix of currently dominant and mature technologies on the one hand and emerging and expensive technologies on the other. In this study, we examine the divergence between long-term domestic and global outcomes when countries make decisions on near-term low-carbon technology investments on the basis of reductions in domestic long-term abatement costs of achieving a long-term global climate change mitigation target. Our analysis shows that under certain assumptions about technological change, the globally cost-effective strategy for achieving a long-term climate goal requires different countries to invest in different technologies. However, under the same technological change assumptions, individual countries have an incentive to invest in the currently mature and cheaper technologies. This divergence between the global cost minimum and individual national cost minimum emerges from the public goods characteristics of technology combined with near-term cost differences for promoting different technologies, which create free-ride problems: the cost-effective strategy for individual countries is to promote the deployment of currently mature and cheaper technologies domestically and free-ride on the benefits of other countries promoting more expensive technologies. The analysis in this paper also shows that when the deployment of the initially expensive low-carbon technologies leads to 
sufficiently rapid technological improvements, which spill over globally, domestic incentives align with the globally cost-effective distribution of technology investments across countries.

The above findings have implications for domestic and international policy. Climate change mitigation is a problem of the global commons that unequivocally requires international action. Our analysis illustrates that if countries make decisions on low-carbon technology deployments driven by domestic incentives and motivations to specialize in specific low-carbon technologies, such decisions could tilt toward currently cheaper alternatives. For instance, countries might prefer to invest in relatively mature low-carbon technologies such as wind and solar over currently emerging and expensive technologies such as CCS (Viebahn et al., 2014), even though such investments might potentially lead to lower costs from the global perspective. Our study argues that there is global benefit in facilitating diversification of investments through collaborative mechanisms. This suggests a role for international cooperation to focus on developing markets and institutions beyond those explicitly related to climate, including those for trade, development, and intellectual property (Newell, 2010). Such cooperation will be all the more important to foster technological change - which will be instrumental in aligning domestic policy objectives with international goals and also address the issues surrounding technological spillovers and free-ride problems.

International cooperation in the research and development of low-carbon technologies is not new (de Coninck et al., 2008), but remains an area of active experimentation. Historically, many controversial issues have influenced (and hindered) international cooperation in low-carbon technology deployment in the context of climate change mitigation. Two particularly thorny issues that bear mention are international trade and intellectual property rights (IPRs). International trade can limit international cooperation in low-carbon technology deployment 
when all countries do not participate in implementing similar policies. For instance, domestic deployment policies and environmental regulations may change relative prices internationally, giving countries not implementing such policies a comparative advantage in emissions-intensive production. Countries could seek to limit comparative disadvantages introduced by domestic policies through trade restrictions, trade sanctions, or by other border adjustment measures (Stavins et al., 2014). However, these measures could strain multilateral trade relations (since the manufacture of almost every good releases greenhouse gases into the atmosphere) and blunt their effectiveness if the costs entailing the decline in trade far exceed environmental benefits (Barrett, 2003; Victor, 2010).

Another issue with regards to international cooperation in the diffusion of low-carbon technologies is intellectual property rights (IPRs). Two opposing views on IPRs make the issue complicated. According to the first view - predominantly that of developing countries - IPRs create barriers to the diffusion of low-carbon technologies in developing countries. Proponents argue that IPRs give a certain degree of monopoly power to the firms owning those rights that can limit the diffusion of new technologies to the developing world by enabling such firms to keep prices prohibitively high. The other view - predominantly that of developed countries - is that IPR protection through patents is one of the principal mechanisms by which innovators can appropriate a portion of the social value of an innovation beyond the boundaries of a firm. IPR protection is therefore important to stimulate and incentivize innovative activity. According to this view, the lack of IPRs in the developing world is a barrier to technology transfer to developing countries and international diffusion of low-carbon technologies will be better facilitated if developing countries tighten their legal frameworks for IPR protection and enforcement (Ockwell et al., 2010). 
An agreement on international cooperation in the broader deployment of diverse low-carbon technologies would obviously require reconciliation of differences such as those discussed above. What complicates the matter further is that in addition to above issues, technological, institutional, and financial heterogeneity across countries influences the deployment of lowcarbon technologies, particularly in developing countries (Iyer et al., 2015a; Iyer et al., 2015b; Iyer et al., 2014). One small but interesting example of a possible way forward is the U.S.-China Clean Energy Research Center (CERC, 2015) in which research is sponsored and results are shared across national borders in a carefully developed legal context. A stable international agreement on low-carbon technology deployment would ultimately rely on a better understanding of the complex processes underlying the development of domestic capabilities (for example, institutional capacities and regulatory environments), especially in developing countries, and their role in fostering the development and diffusion of low-carbon technologies. A detailed examination and critique of possible options to form a stable international agreement on low-carbon technology deployment is beyond the scope of this paper and is reserved for future work.

It is important to note that the conclusions of this study are dependent on one particular formulation of technological change and others are quite possible. First, we assume that increasing the deployment of low-carbon technologies leads to faster reductions in technology costs. However, in the case of some energy technologies such as nuclear, and some manufacturing industries such as aircraft, increase in deployment has led to an increase rather than decrease in technology costs (Argote and Epple, 1990; Cantor and Hewlett, 1988; Cooper, 2010; Grübler, 2010; Hewlett, 1996; Hultman and Koomey, 2007; Hultman et al., 2007; Joskow and Rose, 1985). Second, our results are also dependent on the nature of spillovers. While the 
existence of spillovers is nearly undisputed in the innovation and technological change literature, the nature of spillovers across regional boundaries is unclear. It is plausible that spillovers from abroad cannot be appropriated by domestic firms or such appropriation might be costly and limited by institutional, political and even cultural factors (Braun et al., 2010; Clarke and Weyant, 2002). Hence, results presented for scenarios assuming no additional technological change and different levels of spillovers might be important and merit attention. Finally, we do not consider diversity within countries, that is, the option of countries promoting different technologies domestically, to retain focus on demonstrating the effects of different technology choices on domestic and global outcomes.

The above caveats notwithstanding, the research presented in this paper calls for a solid assessment of technologies in question, their potential for improvement and the nature of spillovers in policy collaborations aimed at undertaking stringent mitigation in the future. Such analyses will provide additional insight on the scope and incentives for nationally determined actions and how international efforts may be most helpful in ensuring that long-term mitigation is achieved cost-effectively.

\section{Acknowledgements}

Research support for G.C.I., L.E.C., J.A.E. and H.C.M. was provided by the Global Technology Strategy Program. N.E.H. was supported by the National Science Foundation under grant number 1056998. This research used Evergreen computing resources at the Pacific Northwest National Laboratory's (PNNL) Joint Global Change Research Institute at the University of Maryland in College Park. PNNL is operated for DOE by Battelle Memorial Institute under 
contract DE-AC05-76RL01830. The views and opinions expressed in this paper are those of the authors alone.

\section{References}

Argote, L., Beckman, S.L., Epple, D., 1990. The persistence and transfer of learning in industrial settings. Management science 36, 140-154.

Argote, L., Epple, D., 1990. Learning Curves in Manufacturing. Science 247, 920-924.

Arrow, K., 1962. The economic implications of learning by doing. The review of economic studies 29, 155-173.

Arthur, W.B., 1989. Competing technologies, increasing returns, and lock-in by historical events. The economic journal 99 116-131.

Barrett, S., 2003. Environment and Statecraft: The Strategy of Environmental Treaty-Making. Oxford University Press.

Barrios, S., Strobl, E., 2004. Learning by doing and spillovers: Evidence from firm-level panel data. Review of Industrial Organization 25, 175-203.

Blanford, G., Clarke, L., 2003. On the optimal allocation of R\&D resources for climate change technology development. Lawrence Livermore National Laboratory, Livermore, CA.

Bloomberg, 2014. China Targets 70 Gigawatts of Solar Power to Cut Coal

Reliance.http://www.bloomberg.com/news/articles/2014-05-16/china-targets-70-gigawatts-of-solarpower-to-cut-coal-reliance.3-Mar,2015

Böhringer, C., Rosendahl, K.E., 2010. Green promotes the dirtiest: on the interaction between black and green quotas in energy markets. Journal of Regulatory Economics 37, 316-325.

Bosetti, V., Carraro, C., Sgobbi, A., Tavoni, M., 2009a. Delayed action and uncertain stabilisation targets. How much will the delay cost? Climatic Change 96, 299-312.

Bosetti, V., Carraro, C., Tavoni, M., 2009b. Climate change mitigation strategies in fast-growing countries: The benefits of early action. Energy Economics 31, S144-S151.

Braun, F.G., Schmidt-Ehmcke, J., Zloczysti, P., 2010. Innovative Activity in Wind and Solar Technology: Empirical Evidence on Knowledge Spillovers Using Patent Data, CEPR Discussion Paper Series 7865.

Cachon, G.P., 2001. Supply chain coordination with contracts, in: de Kok, A.G., Graves, S.C. (Eds.), Handbooks in operations research and management science. Elsevier, pp. 227-339.

Cachon, G.P., Netessine, S., 2004. Game theory in supply chain analysis, Handbook of Quantitative Supply Chain Analysis. Springer, pp. 13-65. 
Cantor, R., Hewlett, J., 1988. The economics of nuclear power: Further evidence on learning, economies of scale, and regulatory effects. . Resources and Energy 10, 315-355.

CERC, 2015. U.S.-China Clean Energy Research Center.http://www.us-china-cerc.org/.February 2,2015

Chester, L., 2010. Conceptualising energy security and making explicit its polysemic nature. Energy Policy 38, 887-895.

Clarke, J.F., Edmonds, J., 1993. Modelling energy technologies in a competitive market. Energy Economics 15, 123-129.

Clarke, L., Calvin, K., Edmonds, J., Kyle, P., Wise, M., 2010. When Technology and Climate Policy Meet: Energy Technology in an International Policy Context, in: Aldy, J.E., Stavins, R.N. (Eds.), PostKyoto International Climate Policy: Implementing Architectures for Agreement: Research from the Harvard Project on International Climate Agreements. Cambridge University Press, Cambridge, UK.

Clarke, L., Edmonds, J., Jacoby, H., Pitcher, H., Reilley, J., Richels, R., 2007. Scenarios of Greenhouse Gas Emissions and Atmospheric Concentrations. Sub-report 2.1A of Synthesis and Assessment Product 2.1 by the U.S. Climate Change Science Program and the Subcommittee on Global Change Research, Department of Energy, Office of Biological and Environmental Research, Washington, DC.

Clarke, L., Weyant, J., Birky, A., 2006. On the sources of technological change: Assessing the evidence. Energy Economics 28, 579-595.

Clarke, L., Weyant, J.P., 2002. Modeling induced technological change: an overview, in: Arnulf, G., Nebojsa, N., D., N.W. (Eds.), Technological Change and the Environment. Resources for the Future, Washington, DC, USA, pp. 320-363.

Clarke, L., Weyant, J.P., Edmonds, J., 2008a. On the sources of technological change: What do the models assume? Energy Economics 30, 409-424.

Clarke, L.E., Wise, M.A., Edmonds, J.A., Placet, M., Kyle, P., Calvin, K., Kim, S.H., Smith, S.J., $2008 b$. $\mathrm{CO}_{2}$ Emissions Mitigation and Technological Advance: An Updated Analysis of Advanced Technology Scenarios. Pacific Northwest National Laboratory, Richland, WA, 2008.

Cooper, M., 2010. Policy Challenges of Nuclear Reactor Construction: Cost Escalation and Crowding Out Alternatives. Institute for Energy and the Environment, Vermont Law School.

de Coninck, H., Fischer, C., Newell, R.G., Ueno, T., 2008. International technology-oriented agreements to address climate change. Energy Policy 36, 335-356.

Edmonds, J., Clarke, J., Dooley, J., Kim, S., Smith, S., 2004. Stabilization of $\mathrm{CO}_{2}$ in a B2 world: insights on the roles of carbon capture and disposal, hydrogen, andtransportation technologies. Energy Economics 26, 517-537.

Edmonds, J., Reilly, J., 1985. Global energy: assessing the future. Oxford University Press, Oxford, U.K. Fankhauser, S., Hepburn, C., Park, J., 2010. Combining multiple climate policy instruments: how not to do it. . Climate change economics 1, 209-225. 
Fischer, C., Newell, R., 2008. Environmental and technology policies for climate mitigation. Journal of environmental economics and management 55, 142-162.

Fudenberg, D., Tirole, J., 1985. Preemption and Rent Equalization in the Adoption of New Technology. The Review of Economic Studies 52, 383-401.

Goulder, L.H., Mathai, K., 2000. Optimal CO2 Abatement in the Presence of Induced Technological Change. Journal of Environmental Economics and Management 39, 1-38.

Grübler, A., 2010. The costs of the French nuclear scale-up: A case of negative learning by doing. Energy Policy 38, 5174-5188.

Grübler, A., Nakićenović, N., Victor, D.G., 1999. Dynamics of energy technologies and global change. Energy Policy 27, 247-280.

Hansen, J.D., Jensen, C., Madsen, E.S., 2003. The establishment of the Danish windmill industry —Was it worthwhile? Review of World Economics 139, 324-347.

Hewlett, J.G., 1996. Economic and Regulatory Factors Affecting the Maintenance of Nucleaer Power Plants. The Energy Journal 4, 1-31.

Hoppe, H.C., 2000. Second-mover advantages in the strategic adoption of new technology under uncertainty. International Journal of Industrial Organization 18, 315-338.

Hultman, N.E., Koomey, J.G., 2007. The risk of surprise in energy technology costs. Environmental Research Letters 2, 034002.

Hultman, N.E., Koomey, J.G., Kammen, D.M., 2007. What history can teach us about the future costs of US nuclear power. Environmental science \& technology 41, 2087-2094.

Irwin, D.A., Klenow, P.J., 1994. Learning-by-doing spillovers in the semiconductor industry. Journal of Political economy 102, 1200-1227.

Iyer, G., Clarke, L., Edmonds, J., Flannery, B., Hultman, N., McJeon, H., Victor, D.G., 2015a. Improved Representation of Investment Decisions in Assessments of $\mathrm{CO}_{2}$ Mitigation. Nature Climate Change 5, 436-440.

Iyer, G., Hultman, N., Eom, J., McJeon, H., Patel, P., Clarke, L., 2015b. Diffusion of low-carbon technologies and the feasibility of long-term climate targets. Technological Forecasting and Social Change. 90, Part A, 103-118.

Iyer, G., Hultman, N., Fetter, S., Kim, S.H., 2014. Implications of small modular reactors for climate change mitigation. Energy Economics 45, 144-154.

Jaffe, A.B., Newell, R.G., Stavins, R.N., 2003. Technological change and the environment, in: Maler, K.G., Vincent, J.R. (Eds.), Handbook of Environmental Economics. Elsevier Science, Amsterdam, pp. 461516.

Jakob, M., Luderer, G., Steckel, J., Tavoni, M., Monjon, S., 2012. Time to act now? Assessing the costs of delaying climate measures and benefits of early action. Climatic Change 114, 79-99. 
Joskow, P.L., Rose, N.L., 1985. The effects of technological change, experience, and environmental regulation on the construction cost of coal-burning generating units. The RAND Journal of Economics, 127.

Junginger, M., Faaij, A., Turkenburg, W.C., 2005. Global experience curves for wind farms. Energy Policy 33, 133-150.

Kahouli-Brahmi, S., 2008. Technological learning in energy-environment-economy modelling: A survey. Energy Policy 36, 138-162.

Kammen, D.M., Kapadia, K., Fripp, M., 2004. Putting Renewables to Work: How Many Jobs Can the Clean Energy Industry Generate? . RAEL Report, University of California, Berkeley.

Kim, S., Edmonds, J., Lurz, J., Smith, S., Wise, M., 2006. The ObjECTS framework for integrated assessment: hybrid modeling of transporation. . Energy Journal 27, 63-91.

Lester, R.K., McCabe, M.J., 1993. The effect of industrial structure on learning by doing in nuclear power plant operation. The Rand Journal of Economics, 418-438.

Lieberman, M.B., 1984. The learning curve and pricing in the chemical processing industries. The RAND Journal of Economics 15, 213-228.

Lieberman, M.B., Montgomery, D.B., 1988. First-mover advantages. Strategic Management Journal 9, 41-58.

McFadden, D., 1980. Econometric models for probabilistic choice among products. The Journal of Business 53, S13-S29.

McJeon, H.C., Clarke, L., Kyle, P., Wise, M., Hackbarth, A., Bryant, B.P., Lempert, R.J., 2011.

Technology interactions among low-carbon energy technologies: What can we learn from a large number of scenarios? Energy Economics 33, 619-631.

Michaels, R., Murphy, R.P., 2009. Green jobs: fact or fiction? Institute for Energy Research, Houston, Texas.

Nemet, G.F., 2012. Subsidies for New Technologies and Knowledge Spillovers from Learning by Doing. Journal of Policy Analysis and Management 31, 601-622.

Newell, R., 2010. International climate technology strategies, in: Aldy, J.E., Stavins, R.N. (Eds.), PostKyoto International Climate Policy: Implementing Architectures for Agreement: Research from the Harvard Project on International Climate Agreements, Cambridge University Press, Cambridge, UK, pp. 403-438.

Ockwell, D.G., Haum, R., Mallett, A., Watson, J., 2010. Intellectual property rights and low carbon technology transfer: Conflicting discourses of diffusion and development. Global Environmental Change 20, 729-738.

Olson, M., 1965. The Logic of Collective Action: Public Goods and the Theory of Groups. Harvard University Press, Cambridge, MA. 
Pethig, R., Wittlich, C., 2009. Interaction of Carbon Reduction and Green Energy Promotion in a Small Fossil-Fuel Importing Economy. CESifo Group Munich, Munich, Germany

Popp, D., Newell, R.G., Jaffe, A.B., 2010. Energy, the Environment, and Technological Change, in: Bronwyn, H.H., Nathan, R. (Eds.), Handbook of the Economics of Innovation. North-Holland, pp. 873937.

REN21, 2013. Renewables 2013 Global Status Report. REN21, Paris, France.

Sands, R., Leimbach, M., 2003. Modeling agriculture and land use in an integrated assessment framework Climatic Change 56, 185-210.

Schneider, S.H., Goulder, L.H., 1997. Achieving low-cost emissions targets. Nature 389, 13-14.

Stavins, R., Ji, Z., Brewer, T., Conte Grand, M., den Elzen, M., Finus, M., Gupta, J., Höhne, N., Lee, M., Michaelowa, A., 2014. International Cooperation: Agreements \& Instruments, in: Edenhofer, O., PichsMadruga, R., Sokona, Y., Farahani, E., Kadner, S., Seyboth, K., Adler, A., Baum, I., Brunner, S., Eickemeier, P., Kriemann, B., Savolainen, J., Schlömer, S., von Stechow, C., Zwickel, T., Minx, J.C. (Eds.), Climate Change 2014: Mitigation of Climate Change, Working Group III contribution to the IPCC 5th Assessment Report. Cambridge University Press, Cambridge, United Kingdom and New York, NY, USA.

The White House, 2014. U.S.-China Joint Announcement on Climate Change.http://www.whitehouse.gov/the-press-office/2014/11/11/us-china-joint-announcement-climatechange.Jan 5, 2014

The White House, 2015. U.S.-Brazil Joint Statement On Climate Change.

Train, K., 1993. Qualitative choice analysis: theory, econometrics, and an application to automobile demand MIT Press.

UNEP, 2008. Green Jobs: Towards decent work in a sustainable, low-carbon world. UNEP/ILO/IOE/ITUC.

UNFCCC, 2010. Report of the Conference of the Parties on its Fifteenth Session (Conf.

Copenhagen,2009). United Nations Framework Convention on Climate Change, Bonn, Germany.

Unruh, G.C., 2000. Understanding carbon lock-in. Energy policy 28, 817-830.

Victor, D.G., 2010. Climate accession deals: New strategies for taming growth of greenhouse gases in developing countries, in: Aldy, J.E., Stavins, R.N. (Eds.), Post-Kyoto International Climate Policy: Implementing Architectures for Agreement: Research from the Harvard Project on International Climate Agreements. Cambridge University Press, Cambridge, UK, pp. 618-648.

Viebahn, P., Vallentin, D., Höller, S., 2014. Prospects of carbon capture and storage (CCS) in India's power sector - An integrated assessment. Applied Energy 117, 62-75.

Vuuren, D., Stehfest, E., Elzen, M.J., Kram, T., Vliet, J., Deetman, S., Isaac, M., Klein Goldewijk, K., Hof, A., Mendoza Beltran, A., Oostenrijk, R., Ruijven, B., 2011. RCP2.6: exploring the possibility to keep global mean temperature increase below $2^{\circ} \mathrm{C}$. Climatic Change 109, 95-116. 
Wei, M., Patadia, S., Kammen, D.M., 2010. Putting renewables and energy efficiency to work: How many jobs can the clean energy industry generate in the US? Energy Policy 38, 919-931.

Yeh, S., Rubin, E.S., 2012. A review of uncertainties in technology experience curves. Energy Economics $34,762-771$.

Yergin, D., 2006. Ensuring energy security. Foreign Affairs, 69-82.

Zimmerman, M.B., 1982. Learning Effects and the Commercialization of New Energy Technologies: The Case of Nuclear Power. The Bell Journal of Economics, 297-310.

NEAR-TERM

Domestic low-carbon technology deployment policies

\section{LONG-TERM}

Global action against climate change

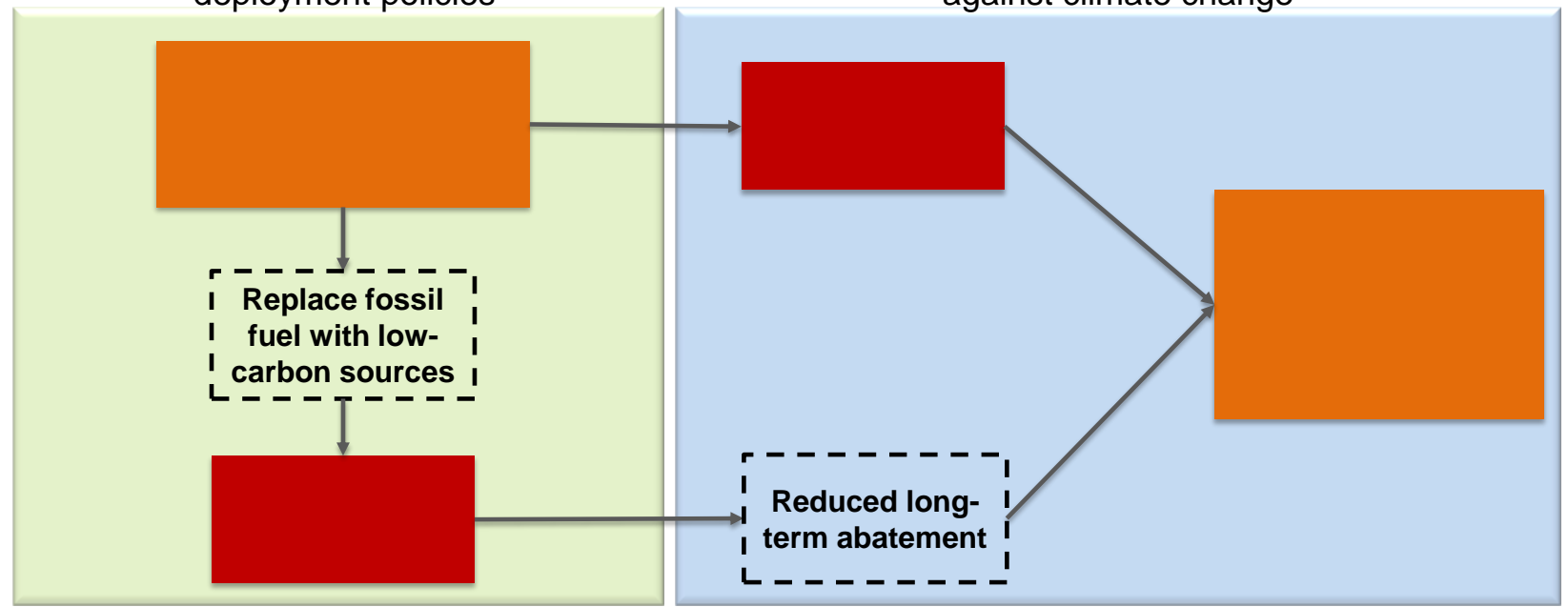

Figure 1 An example of long-term payoffs of near-term low-carbon technology deployment policies in the context of long-term climate change mitigation. Promoting the deployment of low-carbon technologies by means of a deployment policy (such as subsidy or portfolio standard) would lead to reduced abatement costs in the long-term through two effects: the near-term abatement effect and technological change effect. 


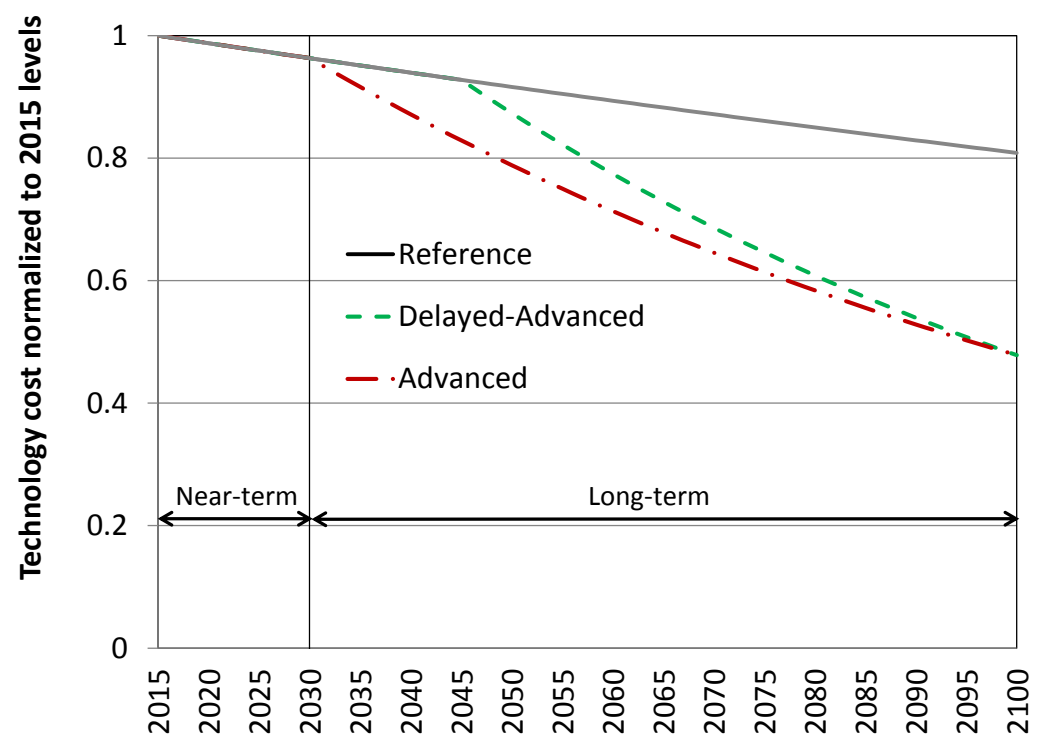

Figure 2 Technology cost functions employed in the technological change scenarios. See Supplementary information for detailed descriptions of the cost functions 
A. Near-term energy system characteristics

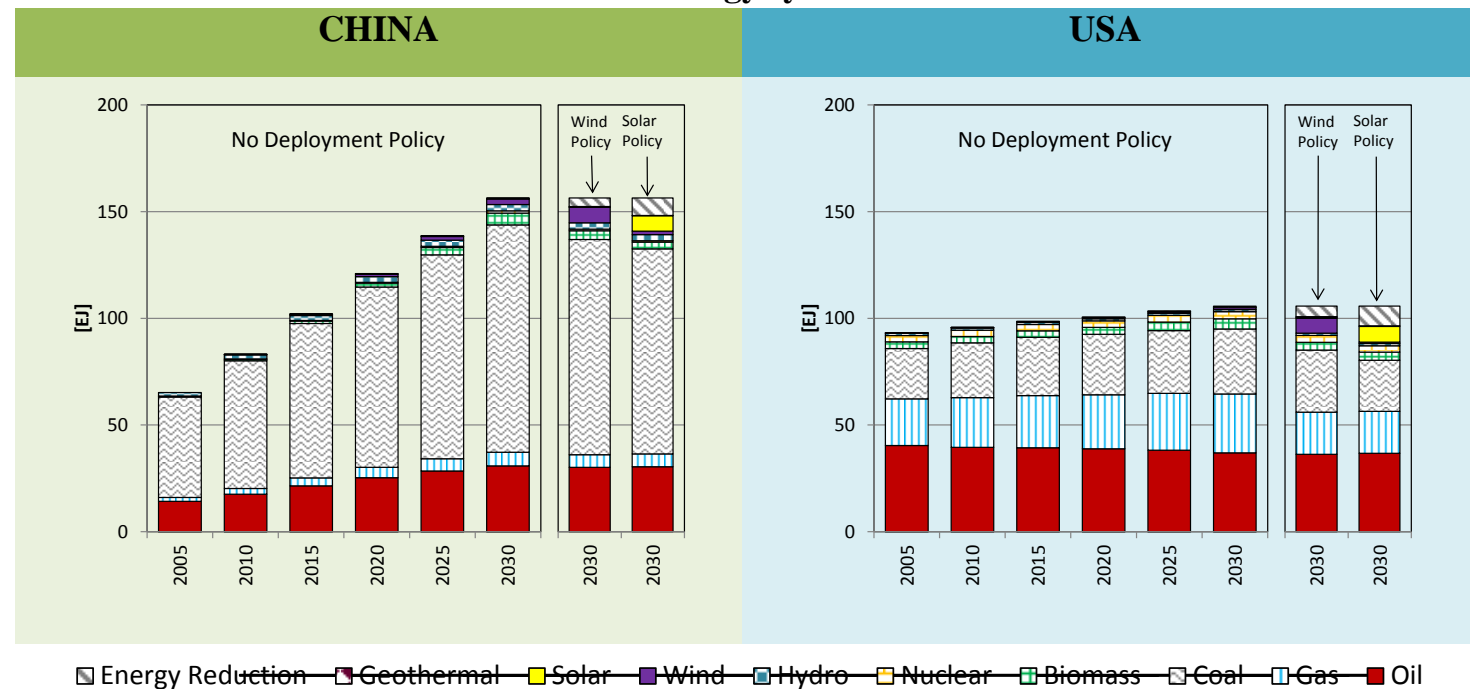

B. Near-term $\mathrm{CO}_{2}$ emissions abatement

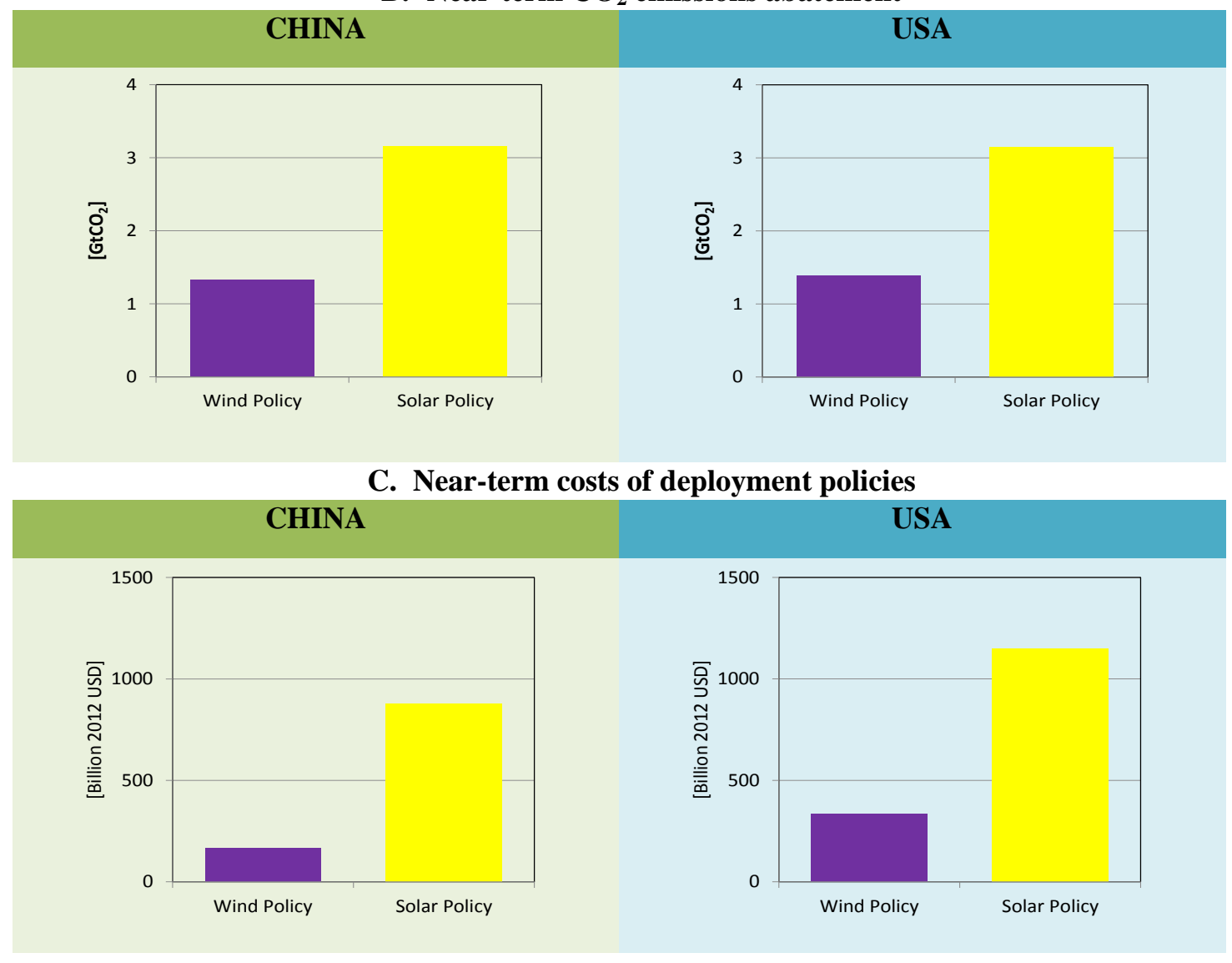

Figure 3 A. Near-term primary energy consumption in China and USA without and with deployment policy. B. Cumulative abatements (2016-2030) in direct $\mathrm{CO}_{2}$ emissions from fossil fuel and industry with respect to the case without deployment policies. C. Net present values of near-term costs (2016-2030) of deployment policies. 


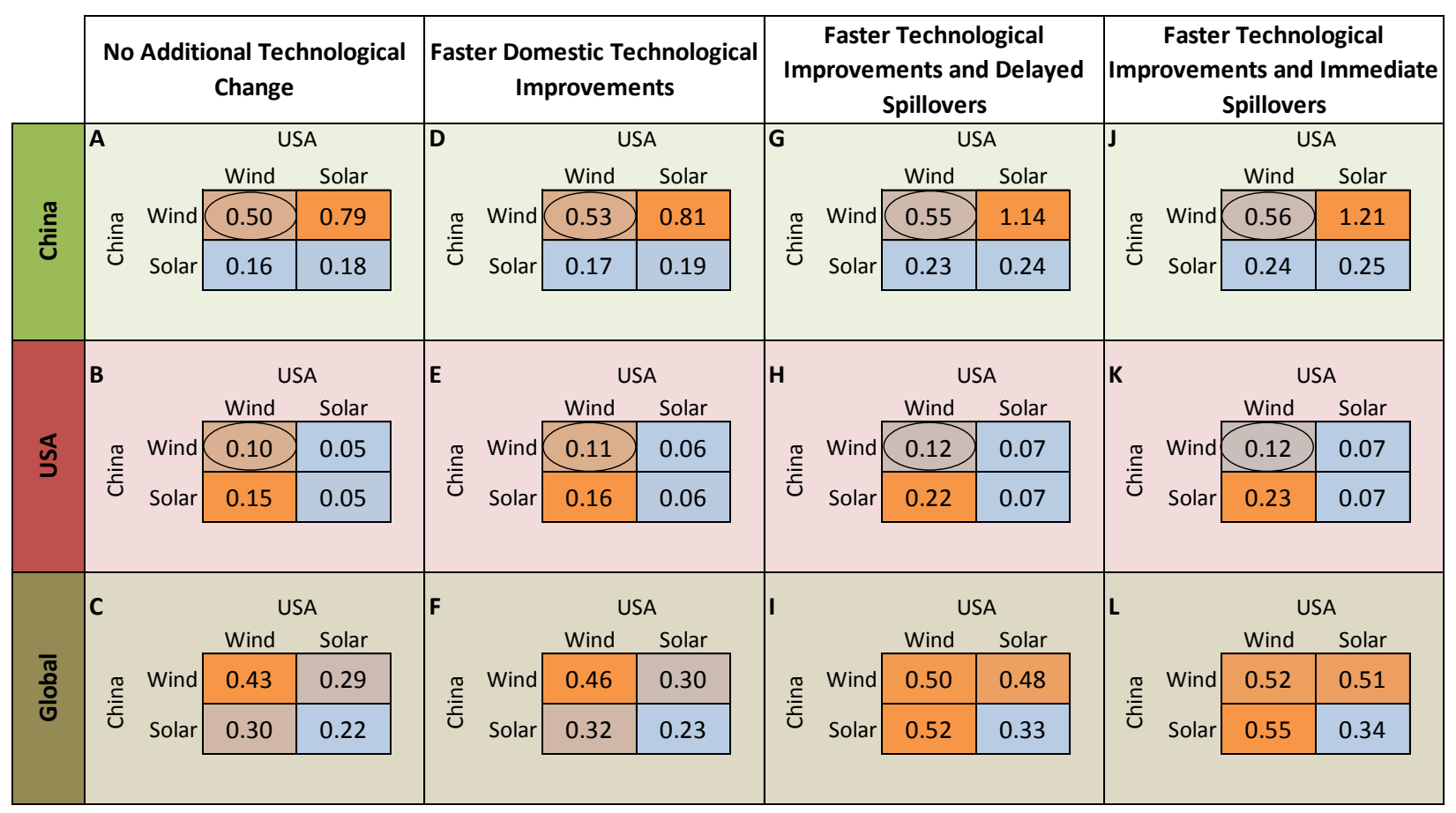

$\begin{array}{lc}\text { Low } & \text { High } \\ \text { payoff } & \text { payoff }\end{array}$

Figure 4 Domestic and global payoffs from reduced long-term abatement costs (reductions in long-term abatement costs relative to the case without near-term deployment policies divided by near-term costs of deployment policies) under central technology cost assumptions (see Supplementary Table 1 for detailed assumptions). The circled payoffs show the Nash equilibrium strategy under a technological change scenario 
China-solar-USA-wind

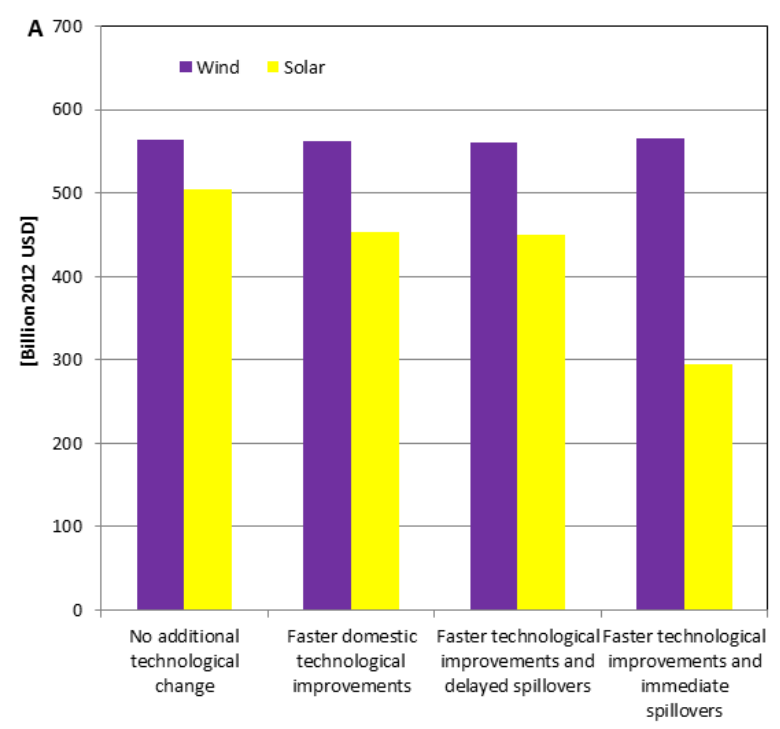

China-wind-USA-solar

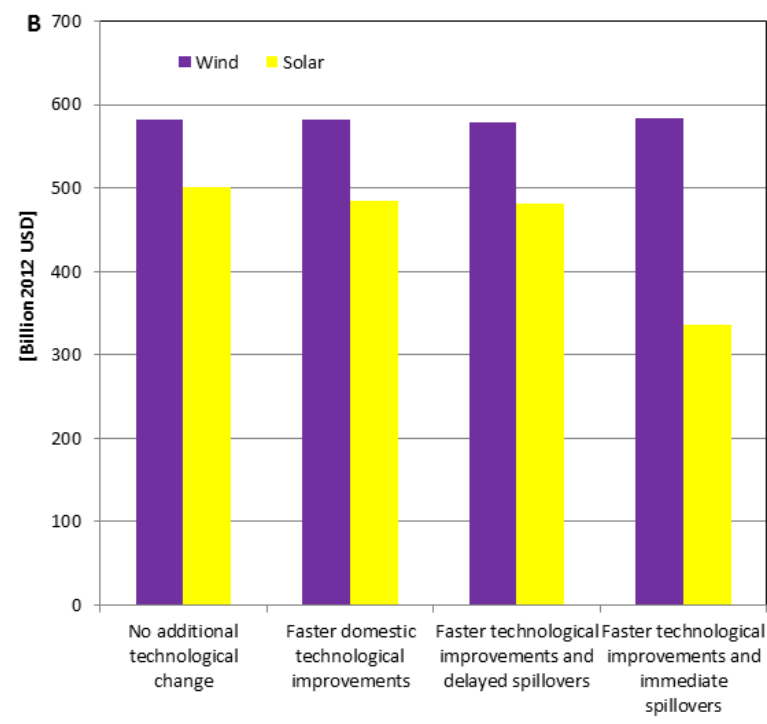

Figure 5 Net present values of global revenues (2031-2050) from the wind and solar markets in the China-solar-USA-wind and China-wind-USA-solar configurations. The cases presented here correspond to central assumptions about technology costs corresponding to analyses presented in Figure 4 (see Supplementary Table 1 for detailed assumptions) 
A. Payoffs for China

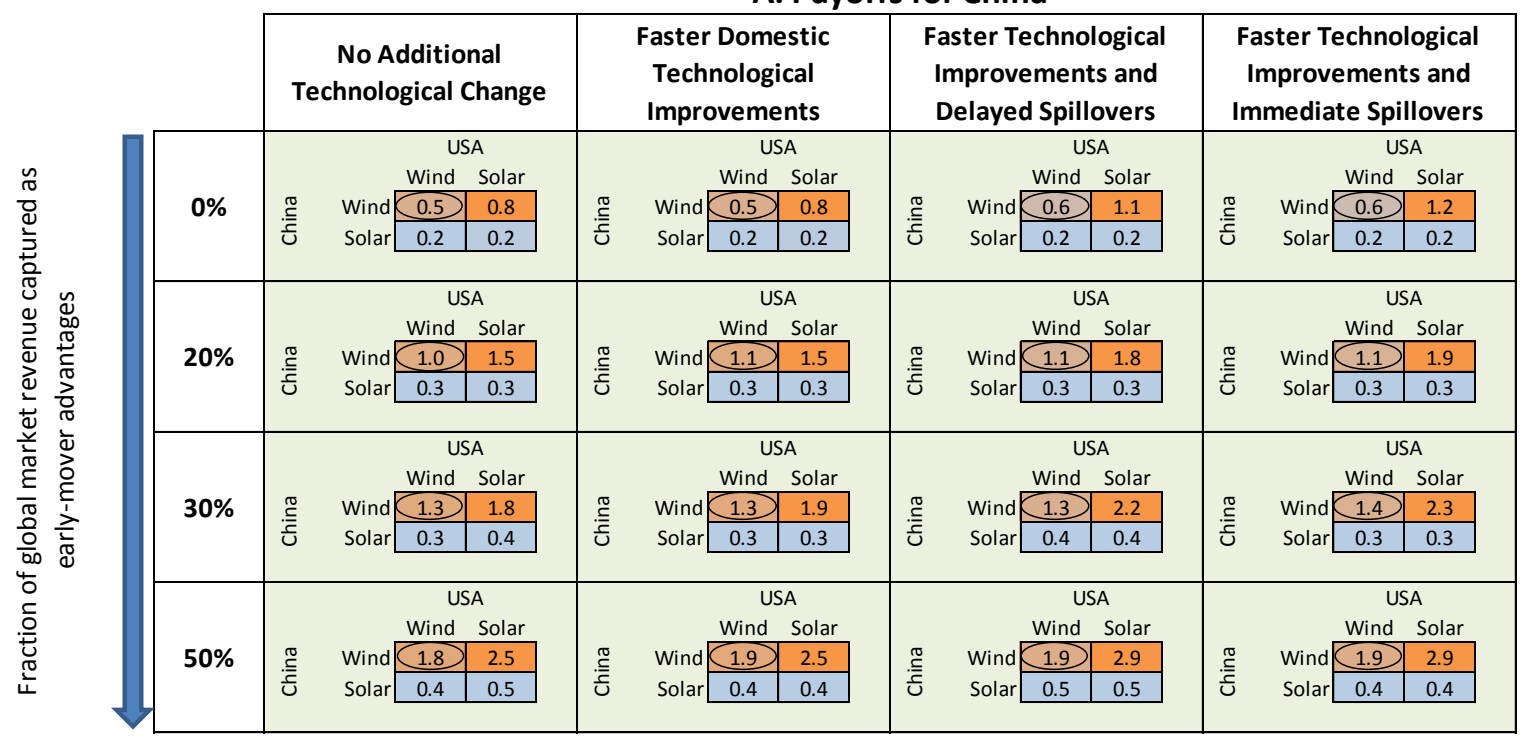

B. Payoffs for USA

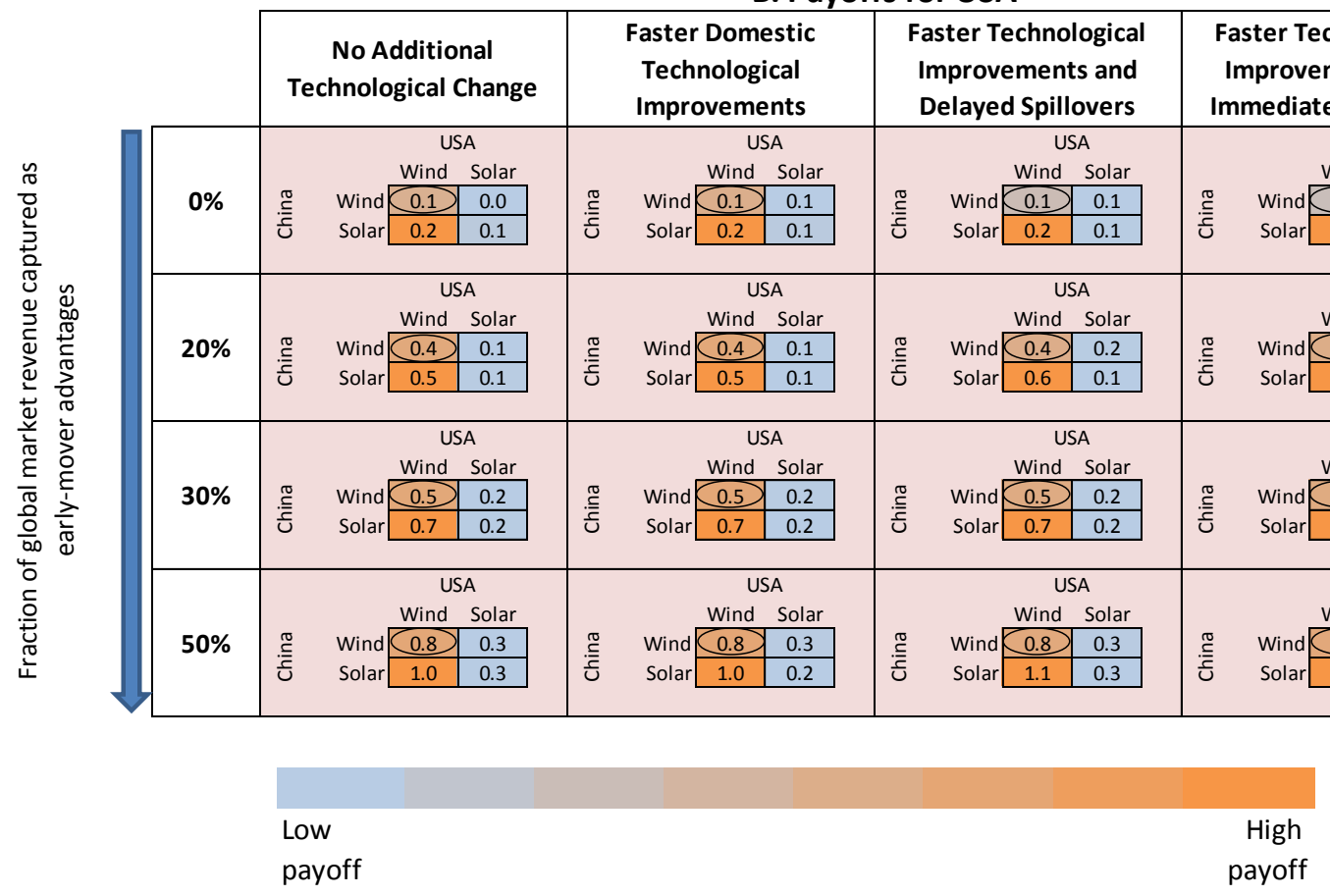

Figure 6 Domestic payoffs from reduced long-term abatement costs and early-mover advantages under central technology cost assumptions corresponding to analyses presented in Figure 3 (see Supplementary Table 1 for detailed assumptions). Early-mover advantages are calculated as a fraction of global market revenue. The circled payoffs show the Nash equilibrium strategy under a technological change scenario for a given fraction of global market that can be captured as early-mover advantages. 


\begin{tabular}{|c|c|c|c|c|c|c|c|c|c|c|c|c|c|c|c|}
\hline \multirow{5}{*}{ 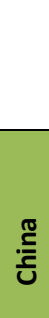 } & \multicolumn{3}{|c|}{$\begin{array}{l}\text { No Additional Technological } \\
\text { Change }\end{array}$} & \multicolumn{4}{|c|}{$\begin{array}{l}\text { Faster Domestic Technological } \\
\text { Improvements }\end{array}$} & \multicolumn{4}{|c|}{$\begin{array}{c}\text { Faster Technological } \\
\text { Improvements and Delayed } \\
\text { Spillovers }\end{array}$} & \multicolumn{4}{|c|}{$\begin{array}{c}\text { Faster Technological } \\
\text { Improvements and Immediate } \\
\text { Spillovers }\end{array}$} \\
\hline & \multirow[t]{2}{*}{ A } & \multicolumn{2}{|c|}{ USA } & \multirow[t]{2}{*}{ D } & & \multicolumn{2}{|c|}{ USA } & \multirow[t]{2}{*}{ G } & \multicolumn{3}{|c|}{ USA } & \multirow[t]{2}{*}{ J } & \multicolumn{3}{|c|}{ USA } \\
\hline & & Wind & Solar & & & Wind & Solar & & \multirow{3}{*}{$\begin{array}{l}\text { Wind } \\
\text { Solar }\end{array}$} & Wind & Solar & & \multirow{3}{*}{$\begin{array}{l}\text { Wind } \\
\text { Solar }\end{array}$} & Wind & Solar \\
\hline & ๘ Wind & 0.50 & 0.79 & \multirow{2}{*}{ 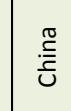 } & Wind & 0.53 & 1.19 & \multirow{2}{*}{ : } & & 0.55 & 9.72 & \multirow{2}{*}{ 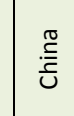 } & & 0.56 & 14.94 \\
\hline & ¿ Solar & 0.16 & 0.18 & & Solar & 1.99 & 2.05 & & & 2.47 & 2.50 & & & 2.85 & 2.86 \\
\hline \multirow{4}{*}{ 气 } & \multirow[t]{2}{*}{ B } & \multicolumn{2}{|c|}{ USA } & \multicolumn{2}{|l|}{ E } & \multicolumn{2}{|c|}{ USA } & \multicolumn{2}{|l|}{ H } & \multicolumn{2}{|c|}{ USA } & \multicolumn{2}{|l|}{ K } & \multicolumn{2}{|c|}{ USA } \\
\hline & & Wind & Solar & & \multirow{3}{*}{$\begin{array}{l}\text { Wind } \\
\text { Solar }\end{array}$} & Wind & Solar & & \multirow{3}{*}{$\begin{array}{l}\text { Wind } \\
\text { Solar }\end{array}$} & Wind & Solar & \multirow{3}{*}{$\stackrel{\frac{\pi}{c}}{\frac{\mathscr{C}}{U}}$} & \multirow{3}{*}{$\begin{array}{l}\text { Wind } \\
\text { Solar }\end{array}$} & Wind & Solar \\
\hline & $\stackrel{\pi}{\subseteq}$ Wind & 0.10 & 0.05 & \multirow{2}{*}{ 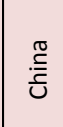 } & & 0.11 & 0.55 & \multirow{2}{*}{ 胥 } & & 0.12 & 0.69 & & & 0.12 & 0.83 \\
\hline & ธ์ Solar & 0.15 & 0.05 & & & 0.33 & 0.58 & & & 1.88 & 0.71 & & & 2.85 & 0.83 \\
\hline & C & US & & $\mathbf{F}$ & & & & I & & & & L & & & \\
\hline & & Wind & Solar & & & Wind & Solar & & & Wind & Solar & & & Wind & Solar \\
\hline 증 & 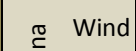 & 0.43 & 0.29 & ฮే & Wind & 0.46 & 0.91 & $\stackrel{\pi}{\complement}$ & Wind & 0.50 & 4.75 & $\stackrel{\pi}{\complement}$ & Wind & 0.52 & 6.60 \\
\hline ত & ¿ Solar & 0.30 & 0.22 & ปे & Solar & 2.06 & 1.64 & ป & Solar & 5.55 & 3.46 & ป & Solar & 7.16 & 4.29 \\
\hline
\end{tabular}

\section{Low} payoff
High

payoff

Figure 7 Domestic and global payoffs from reduced long-term abatement costs (reductions in long-term abatement costs relative to the case without near-term deployment policies divided by near-term costs of deployment policies) assuming that promoting solar technologies leads to a breakthrough in solar technologies (see Supplementary Table 1 for more a detailed description of the assumptions). The circled payoffs show the Nash equilibrium strategy under a technological change scenario.

Table 1 Summary of key assumptions

\begin{tabular}{|c|l|l|}
\hline Variable & \multicolumn{1}{|c|}{ Near-term } & \multicolumn{1}{c|}{ Long-term } \\
\hline Period & 2016-2030 & 2031-2100 \\
\hline Policy mechanism & $\begin{array}{l}\text { Deployment policy (renewable } \\
\text { portfolio standard) }\end{array}$ & Global carbon price \\
\hline Policy stringency & $\begin{array}{l}500 \text { GW cumulative installed } \\
\text { capacity by 2030 }\end{array}$ & $550 \mathrm{ppm} \mathrm{CO}_{2}$ e by 2100 \\
\hline Near-term costs & $\begin{array}{l}\text { Change in consumer and } \\
\text { producer surplus due to policy }\end{array}$ & NA \\
\hline $\begin{array}{c}\text { Long-term } \\
\text { payoffs }\end{array}$ & NA & $\begin{array}{l}\text { Reduced long-term abatement } \\
\text { costs* }\end{array}$ \\
\hline
\end{tabular}

*Abatement costs are calculated as area under the marginal abatement cost curve 
Table 2 Technological change scenarios to study the technological change effect. See Figure 2 and supplementary information for representations of reference, advanced and delayedadvanced technology costs

\begin{tabular}{|c|c|c|}
\hline Technological change scenario & \multicolumn{2}{|c|}{ Technology costs in the long-term } \\
\hline $\begin{array}{c}\text { Near-term deployment policy } \\
\text { leading to }\end{array}$ & $\begin{array}{c}\text { Region with } \\
\text { deployment policy }\end{array}$ & $\begin{array}{c}\text { Region without } \\
\text { deployment policy }\end{array}$ \\
\hline $\begin{array}{c}\text { No additional technological } \\
\text { change }\end{array}$ & Reference & Reference \\
\hline $\begin{array}{c}\text { Faster domestic technological } \\
\text { improvements }\end{array}$ & Advanced & Reference \\
\hline $\begin{array}{c}\text { Faster technological } \\
\text { improvements and delayed } \\
\text { spillovers }\end{array}$ & Advanced & Delayed-Advanced \\
\hline $\begin{array}{c}\text { Faster technological } \\
\text { improvements and immediate } \\
\text { spillovers }\end{array}$ & Advanced & Advanced \\
\hline
\end{tabular}

Table 3 Near-term deployments of wind and solar without and with deployment policy in China and USA.

\begin{tabular}{|c|c|c|c|c|c|c|}
\hline \multirow{3}{*}{ Country } & \multicolumn{4}{|c|}{2030 Cumulative deployments } & \multirow{2}{*}{\multicolumn{2}{|c|}{$\begin{array}{l}2030 \text { additional } \\
\text { deployment with } \\
\text { deployment policy }\end{array}$}} \\
\hline & \multicolumn{2}{|c|}{$\begin{array}{l}\text { Without deployment } \\
\text { policies } \\
\text { [GW] }\end{array}$} & \multicolumn{2}{|c|}{$\begin{array}{c}\text { With deployment } \\
\text { policies } \\
{[G W]}\end{array}$} & & \\
\hline & Wind & Solar & Wind & Solar & Wind & Solar \\
\hline China & 177 & 11 & 500 & 500 & 323 & 489 \\
\hline USA & 62 & 4 & 500 & 500 & 438 & 496 \\
\hline
\end{tabular}

